\title{
Application of ITC in foods: A powerful tool for understanding the gastrointestinal fate of lipophilic compounds
}

\author{
Izlia J. Arroyo-Mayas, David Julian McClements*. \\ Department of Food Science, University of Massachusetts, Amherst, MA, 01003, USA. \\ \$Present address: Departamento de Procesos y Tecnología, Universidad Autónoma \\ Metropolitana-Cuajimalpa, Cuajimalpa, D.F. 05300, México
}

\section{Corresponding Author}

David Julian McClements. mcclements@foodsci.umass.edu

Phone number: +413-545-1019

Fax number: $+413-545-1262$

\begin{abstract}
Background: Isothermal titration calorimetry (ITC) is a biophysical technique widely used to study molecular interactions in biological and non-biological systems. It can provide important information about molecular interactions (such as binding constant, number of binding sites, free energy, enthalpy, and entropy) simply by measuring the heat absorbed or released during an interaction between two liquid solutions.
\end{abstract}


Scope of the review: In this review, we present an overview of ITC applications in food science, with particular focus on understanding the fate of lipids within the human gastrointestinal tract. In this area, ITC can be used to study micellization of bile salts, inclusion complex formation, the interaction of surface-active molecules with proteins, carbohydrates and lipids, and the interactions of lipid droplets.

Major conclusions: ITC is an extremely powerful tool for measuring molecular interactions in food systems, and can provide valuable information about many types of interactions involving food components such as proteins, carbohydrates, lipids, surfactants, and minerals. For systems at equilibrium, ITC can provide fundamental thermodynamic parameters that can be used to establish the physiochemical origin of molecular interactions

\section{General significance:}

It is expected that ITC will continue to be utilized as a means of providing fundamental information about complex materials such as those found in foods. This knowledge may be used to create functional foods designed to behave in the gastrointestinal tract in a manner that will improve human health and well-being.

Keywords: foods; digestion; gastrointestinal; binding; micelles; aggregation 


\section{Introduction}

Isothermal titration calorimetry (ITC) is an extremely powerful tool that can be used to provide valuable information in many areas of food science. In this article, we focus on a particular application of ITC to highlight its great potential: the gastrointestinal fate of ingested lipids. Understanding the behavior of lipids within the gastrointestinal tract (GIT) has recently become an important area of research within the food industry due to the focus on designing foods to increase human health and wellness. For example, functional foods are being designed to improve the bioavailability profile or control the delivery of hydrophobic nutraceuticals, nutrients, and vitamins [1-3]. A number of bioactive hydrophobic components that might be incorporated into food and beverages are listed in Table 1.

The gastrointestinal fate of food lipids within the human body is a complex process that depends on many factors, including the nature of the delivery system used, food matrix effects, and the concentration and nature of the lipids [4]. A number of physicochemical and physiological processes influence the absorption of dietary lipids. Triacylglycerols (TAG) undergo digestion within the stomach and small intestine due to the presence of gastric and pancreatic lipases, which leads to the formation of free fatty acids (FFA) and monoacylglycerols (MAG). These surface-active lipid digestion products interact with endogenous surface-active lipids (bile salts and phospholipids) to form micelles, vesicles, and other colloidal structures [5]. These "mixed micelles" are capable of solubilizing lipophilic bioactive components and transporting them to the epithelium cells where they are absorbed. Lipid digestion is therefore a critical step in ensuring good absorption of ingested lipophilic bioactives [6]. The GIT fate of lipids is influenced by their interaction with other species within the food matrix or within the gastrointestinal fluids, and therefore it is important to understand the nature of these interactions and their impact on lipid digestion and absorption [7].

\section{Gastrointestinal fate of lipids}

\subsection{Lipid bioavailability}

Oral bioavailability can be defined as the fraction of an ingested component (or its metabolic products) that eventually ends up in the systemic circulation $[8,9]$. For lipophilic components, the overall bioavailability $(\mathrm{F})$ can be defined as [9]: 


$$
\mathrm{F}=\mathrm{F}_{\mathrm{B}} \times \mathrm{F}_{\mathrm{A}} \times \mathrm{F}_{\mathrm{T}}
$$

Here, $\mathrm{F}_{\mathrm{B}}$ is the bioaccessibility coefficient or the fraction of lipophilic components released from the food matrix into the GIT fluids; $\mathrm{F}_{\mathrm{A}}$ is the absorption coefficient or the fraction of bioaccessible lipophilic components absorbed by the intestinal epithelium; and, $\mathrm{F}_{\mathrm{T}}$ is the transformation coefficient or the fraction of lipophilic components that reach the systemic circulation in a metabolically active form. After the lipophilic components reach the systemic circulation they are distributed between different tissues, where they may be stored, utilized, or excreted [9]. The relative rates of these various processes determine the time-dependence of the concentrations of the ingested lipophilic components and their metabolites at specific locations within the human body. The concentration-time profile of a specific lipid at a particular site-ofaction determines its beneficial or adverse effects on human health. Consequently, it is important to establish the concentration-time profile of lipid components at particular locations within the human body to establish its efficacy [10].

\subsection{Changes in environmental conditions within the GIT}

An overview of some of the major factors that would be expected to alter the rate and extent of lipid digestion is given in this section so as to better understand the potential applications of ITC for understanding these complex processes [1,2]. After ingestion a food experiences a series of physical and chemical changes as it passes through the mouth, stomach, small intestine and colon, which may directly or indirectly alter the bioaccessibility, absorption, and transformation of lipids (Fig. 1). Some of the key environmental changes that ITC may be able to provide valuable information about are summarized below:

(i) $\mathrm{pH}$ : The $\mathrm{pH}$ of the aqueous phase surrounding the lipids in a food may change appreciably as they pass through the human GIT: mouth $(\mathrm{pH} \approx 7)$; stomach $(\mathrm{pH} \approx 1-3)$; small intestine $(\mathrm{pH} \approx 5.5-7)$; and colon $(\mathrm{pH} \approx 6-7.5)$. These $\mathrm{pH}$ changes lead to alterations in the electrical characteristics of lipid molecules, as well as many other components within the GIT (such as surfactants, bile salts, proteins, and polysaccharides), which may lead to changes in their interactions, structural organization, and gastrointestinal fate. ITC may be used to characterize interactions between different types of electrically charged species, since there is usually an enthalpy change associated with electrostatic interactions. 
(ii) Ionic composition: There are considerable alterations in ionic composition of the aqueous phase surrounding lipids depending on their location within the GIT and the nature of the original food matrix. The ionic composition impacts electrostatic interactions between charged species through screening and binding effects. For example, anionic fatty acids may precipitate in the presence of cationic calcium ions, thereby altering lipid digestion and absorption [11]. Consequently, it is often important to determine how ions influence electrostatic interactions within the GIT, and how these interactions alter the gastrointestinal fate of lipids. ITC is a particularly powerful tool for characterizing the influence of ionic composition on interactions between molecular species (Section 3).

(iii) Surface-active components: The GIT contains a complex mixture of different surface active components that may be ingested food ingredients (such as surfactants, phospholipids, polysaccharides, and proteins), secreted by the body (such as enzymes, phospholipids, and bile salts), or generated during passage of a food through the GIT (such as peptides, FFAs, and MAGs). These surface-active substances may alter the formation, stability, and properties of lipid droplets within the GIT, and may also alter the ability of digestive enzymes to hydrolyze lipids $[12,13]$. ITC has proved to be a useful tool for understanding the micellization of surface-active substances, as well as their interactions with other components (Section 3).

(iv) Enzyme activity: There are numerous types of digestive enzymes within the GIT that can breakdown major food components, such as lipids (lipases), phospholipids (phospholipases), proteins (proteases), and starch (amylases) [14]. The ability of these enzymes to interact with their substrates within the GIT may directly or indirectly impact lipid digestibility, and therefore impact the absorption of any encapsulated lipophilic components [15]. ITC is a powerful method that can be used to monitor enzyme reactions due to enthalpy changes associated with hydrolysis of food components.

(v) Temperature: There may be a large change in temperature from the initial food to the human body, which may cause changes in the physical state, molecular conformation, or interactions of food components that impact digestibility, e.g., fat melting or biopolymer conformational changes. Differential scanning calorimetry (DSC) is particularly suitable 
for monitoring phase changes of specific components, but ITC may be used to determine how changes in molecular properties alter the interactions of ingested components.

(vi) Flow/force profile: Foods are exposed to various kinds of force/flow profiles during their passage through the human body, which are responsible for mixing different components together, as well as fragmenting structures such as bulk oils, solid particles, and hydrogel matrices [14]. ITC instruments usually have a stirrer within the reaction chamber whose speed can be varied, and therefore it may be possible to utilize this to simulate some of the flow/force profiles experienced by foods as they pass through the GIT. Nevertheless, it is unlikely that the complex flow/force profiles occurring within the human GIT can be accurately simulated. It is also possible to vary the rate at which the fluid in the injector is titrated into the reaction chamber of an ITC instrument, which gives some flexibility in mimicking biological processes such as intestinal secretions.

An improved knowledge of how foods behave under complex GIT conditions can be utilized to create functional foods designed to enhance lipid bioavailability [16].

\subsection{Behavior of lipids within different locations in the GIT}

Foods may undergo various changes in their composition and structure as they pass through the GIT due to the alterations in their environment discussed in the previous section. In this section, we provide a brief overview of the physicochemical and physiological processes that foods are exposed to within the human GIT.

Mouth: After being consumed, foods are mixed with saliva in the mouth, which leads to changes in $\mathrm{pH}$, ionic strength, temperature, and enzyme activity (particularly amylases). In addition, they may interact with biopolymers (such as mucin) in the saliva, as well as with the surfaces of the oral cavity. The movements of the tongue and palate produce flow/force profiles that mix the different components in the mouth, breakdown large objects, and facilitate swallowing [17]. Ingested lipids may undergo appreciable changes in their composition, structural organization, and physical state as a result of their exposure to oral conditions.

Stomach: After swallowing, foods travel through the esophagus and enter the gastric cavity where they are subjected to strongly acidic conditions, digestive enzymes (such as gastric proteases and lipases), surface-active substances (such as phospholipids and proteins), and complex flow/force profiles $[18,19]$. The surface-active substances may adsorb to any oil-water 
interfaces and alter the interfacial composition. The gastric lipases and proteases begin the processes of lipid and protein hydrolysis. The changes in $\mathrm{pH}$ and ionic strength may lead to appreciable changes in the aggregation state and interfacial properties of lipid droplets.

Small intestine: After leaving the stomach the partially digested food components move into the small intestine through the pylorus sphincter. Here they are mixed with small intestinal fluids that contain mineral ions, bile salts, phospholipids, pancreatic enzymes, and various other components. Alkaline bicarbonates in the intestinal fluids cause the $\mathrm{pH}$ to increase to around neutral. Surface-active substances in the intestinal fluids may adsorb to oil-water interfaces and alter their properties, or they may interact with other food components (such as polysaccharides and proteins). Pancreatic enzymes, such as lipase, protease, and amylase, hydrolyze lipids, proteins, and starches and convert them into smaller molecular species that can be adsorbed by the epithelium cells. Lipid digestion products, such as monoacylglycerols (MAGs) and free fatty acids (FFAs), interact with bile salts and phospholipids to form mixed micelles that transport them to the epithelium cells where they are absorbed (Fig. 2) [20]. Bioactive lipids (such as nutraceuticals and vitamins) that may be dissolved in digestible lipids (such as TAGs) may also be incorporated into the mixed micelles and transported to the surfaces of the epithelium cells where they are absorbed [21, 22]. Food components such as surfactants, proteins, and polysaccharides may interfere with these processes and therefore alter lipid bioavailability [1, 22].

\section{Characterizing interactions amongst food components using ITC}

The gastrointestinal fate of lipids is influenced by their interactions with various kinds of molecular species within the GIT. In this section, some of the applications of ITC for studying the interactions of both polar lipids (such as surfactants) and non-polar lipids (such as TAGs) with molecular species that may be found in the human GIT are discussed.

\subsection{Principles of ITC}

The previous section has highlighted the complex interactions that may occur within the human GIT, and how an understanding of these interactions may be used to control the bioactivity of lipophilic components. ITC can provide important information about the thermodynamics of molecular interactions by measuring the heat absorbed or released when two 
solutions containing different molecular species are mixed [23]. ITC can therefore be used to provide valuable information about molecular interactions that impact the GIT fate of lipids, such as binding of small molecules to biopolymers, biopolymer-biopolymer interactions, enzyme activities, and micelle formation by surface-active substances.

The theoretical and practical aspects of ITC have been discussed in detail elsewhere [24, 25], and so only a brief overview is given here using molecular binding interactions as an example. In this case, small aliquots of a solution containing a ligand are injected into a reaction chamber containing another solution containing the sample molecules (Fig. 3). The heat released (exothermic) or absorbed (endothermic) by the molecular interaction $(q)$ is measured by determining the power necessary to maintain a constant temperature difference between the reference and sample solution. As the titration reaction proceeds, the binding sites become saturated and so the reaction heat tends towards zero. A plot of reaction heat versus time can be integrated to give a plot of the change in interaction enthalpy with ligand-sample molar ratio or ligand concentration. The resulting binding isotherm can be analyzed to determine the binding enthalpy $(\Delta H)$, the equilibrium binding affinity $\left(K_{a}=1 / K_{d}\right)$, and the number of binding sites $(N)$. These parameters can then be used to calculate the Gibbs free interaction energy $(\Delta G)$ and the entropy contribution $(-T \Delta S)$ :

$$
\begin{aligned}
& \Delta G=-R T \ln K_{a} \\
& \Delta G=\Delta H-T \Delta S
\end{aligned}
$$

Here, $R$ is the gas constant $\left(8.314 \mathrm{~J} \mathrm{~K}^{-1} \mathrm{~mol}^{-1}\right)$ and $T$ is the absolute temperature (in $\mathrm{K}$ ). The binding enthalpy $(\Delta H)$ is temperature dependent, and measurement of its value at different temperatures allows calculation of the binding heat capacity $\left(\Delta C_{p}\right)$ :

$$
C_{p}=\delta \Delta H / \delta T
$$

Thus, ITC experiments can be used to provide a number of important thermodynamic parameters about equilibrium binding events. Nevertheless, it should be mentioned that many of the interactions occurring in the GIT are not at equilibrium, and therefore the above analysis is not strictly applicable. In addition, many of the interactions are not simple binding interactions, and 
may also involve other molecular events that may alter the enthalpy, such as conformational changes or aggregation.

Traditionally, ITC has been used to study highly specific protein-protein or protein-small molecule interactions, however, there is increasing interest in using it to analyze more complex systems. For example, ITC has been used to measure enthalpy changes associated with interactions in colloidal systems, such as dissociation of surfactant micelles [26-28], binding of surfactants to polymers [29-31], adsorption of surface-active molecules to colloidal particles [3234], and partitioning of molecules in aqueous micellar solutions [35, 36]. In addition, ITC has previously been used to monitor enzyme hydrolysis reactions [37-39], which may be useful for studying the digestion of food components (such as proteins, carbohydrates, and lipids) under simulated GIT conditions.

\subsection{Bile salt micellization}

Bile salts are natural surface-active molecules secreted by the human body that play important roles in lipid digestion: they aid in the formation and stabilization of emulsified lipids within the GIT, as well as solubilizing and transporting lipid digestion products (MAGs and FFAs) and bioactive lipids to the epithelium cells [40]. Consequently, it is important to understand the behavior of bile salts within the GIT and the major factors that alter their behavior. Bile salt micelles tend to have much smaller aggregation numbers than conventional small molecule surfactants [41], and micellization tends to proceed over a broader range of concentrations [42]. These differences have been attributed to their plate-like structures of bile

salts, which are very different from the polar head/non-polar tail structure of conventional small molecule surfactants. The critical micelle concentration (CMC) and demicellization enthalpy $\left(\Delta H_{\text {demic }}\right)$ of the primary aggregates formed by sodium cholate $(\mathrm{NaC})$ and sodium deoxycholate (NaDC) in aqueous solutions has been characterized using ITC [40]. It was reported that the $\mathrm{CMC}$ of $\mathrm{NaC}$ and $\mathrm{NaDC}$ was a minimum between 295 and $300 \mathrm{~K}$. With increasing ionic strength the $\mathrm{CMC}$ of the bile salts decreased due to electrostatic screening effects. $\Delta H_{\text {demic }}$ was strongly temperature-dependent, but showed almost no dependence on ionic strength. At the CMC the aggregation number $(n)$ of the micelles was estimated to be around six for $\mathrm{NaC}$ in $0.1 \mathrm{M} \mathrm{NaCl}$ solution and independent of temperature. Under similar conditions, the aggregation number for $\mathrm{NaDC}$ was determined to be around 12 and 7 at 284 and $328 \mathrm{~K}$, respectively [40]. These 
measurements were interpreted in terms of the amount of hydrophobic surface area exposed to water in the micelles [43, 44]. ITC has also been used to examine the interaction of bile salt micelles with other components in the GIT (see later).

\subsection{Interactions involving other lipids}

The non-polar lipids (such as TAGs) in many foods are present as a dispersion of small oil droplets in water, i.e., oil-in-water emulsions [45-47]. The behavior of oil droplets within the GIT is strongly influenced by their interfacial properties and aggregation state [47, 48]. Consequently, it is important to determine how these characteristics change as emulsified lipids pass through the various regions of the GIT and are exposed to different environments within the gastrointestinal fluids [47]. Surface-active lipids, such as surfactants and bile salts, may interact with oil droplets and change their interfacial composition through competitive adsorption processes. In addition, they may promote flocculation or coalescence of oil droplets by altering the colloidal interactions between them. Consequently, it is important to understand how oil droplets interact with surface-active lipids.

ITC has been used to measure enthalpy changes resulting from titration of sodium dodecyl sulfate (SDS) micelles into silicone oil-in-water emulsions containing monodisperse droplets of different diameters [49]. The results of this study indicated that SDS micelles increased the attraction between the oil droplets through a depletion mechanism, which promoted flocculation when the surfactant concentration exceeded a critical concentration. This study suggested that ITC might provide valuable information about droplet-droplet interactions in emulsions, which may be useful in understanding the factors influencing the aggregation of lipid droplets in the GIT.

It should be noted that it is often difficult to obtain fundamental information about enthalpy, entropy, and free energy changes associated with specific molecular events when ITC is used to study interactions involving lipids. This is because there may be multiple molecular events simultaneously occurring during an interaction which makes interpretation more difficult, such as micelle formation/dissociation, alterations in aggregation state, and conformational changes, as well as binding phenomenon. Nevertheless, in relatively simple situations it is possible to obtain this type of fundamental information. For example, the binding constants and number of 
binding sites have been determined from ITC measurements for interactions between surfactants and cyclodextrins $[50,51]$ and surfactants and polyelectrolytes [52]

\subsection{Interactions involving carbohydrates}

Polar lipids, such as small molecule surfactants, phospholipids and bile salts, may interact with various types of carbohydrates within foods and within the GIT. These interactions may alter lipid bioavailability by changing their bioaccessibility, absorption, or transformation. For example, if bile salts bind strongly to carbohydrates, then they may not be available to facilitate lipid emulsification, or the solubilization and transport of lipid digestion products. Various types of carbohydrates may be present in foods including monosaccharides, oligosaccharides, and polysaccharides, which vary in their molecular, physicochemical, and nutritional properties. At the molecular level, they may vary in terms of chain length, branching, conformation, flexibility, polarity, and electrical characteristics. At the physicochemical level, they may vary in terms of their water-solubilities, thickening properties, and gelation properties. At the nutritional level they may be digestible or non-digestible. Understanding the impact of different carbohydrate characteristics on the GIT fate of lipids is therefore important.

Bile salt - polysaccharide interactions: The binding of bile salts to dietary fibers within the small intestine has been proposed as a mechanism for the reduction of blood cholesterol levels. Bile salts are synthesized from cholesterol in the liver and are then secreted into the duodenum by enterohepatic circulation [53-55]. Normally, most bile salts are reabsorbed by the GIT and returned to the liver so that the bile salt pool remains constant $[53,54]$. The ability of certain dietary fibers to reduce cholesterol levels has been attributed to their ability to interfere with the re-absorption of bile salts. ITC has been used to characterize the influence of ionic strength and temperature on the binding of sodium taurocholate (NaTC) to a cationic polysaccharide (chitosan) [56]. It was reported that NaTC bound strongly to chitosan, Fig. 4 shows the enthalpy change when NaTC was injected into a chitosan solution, this figure indicates that ITC is a powerful tool for studying interactions between bile salts and food grade biopolymers; the result of this interaction was the formation of an insoluble complex that contained about 4 mmol of NaTC per $1 \mathrm{~g}$ of chitosan at saturation. It was also observed that the presence of salt decreased the critical micelle concentration (CMC) of NaTC (in both the absence and presence of chitosan), increased the minimum NaTC concentration required for binding to be observed, but 
had little influence on the amount of NaTC bound to chitosan at saturation. The enthalpy changes associated with micelle dissociation went from exothermic at low-holding temperatures to endothermic at higher holding temperatures. Conversely, the enthalpy changes associated with NaTC-chitosan binding went from endothermic at low-holding temperatures to exothermic at higher holding temperatures. The temperature dependence of these processes indicated the importance of changes in hydrophobic interactions within the systems (Fig. 5) [56]. The binding of bile salts to dietary fibers in the GIT may influence their ability to emulsify lipids and transport lipid digestion products, which could impact lipid bioavailability.

Bile salt - maltodextrin interactions: Maltodextrins are digestive byproducts of starch that contain linear amylose and branched amylopectin degradation products [57, 58]. They are widely used in the food industry as functional ingredients to provide texture, stability, appearance and flavor characteristics to foods [58-60]. Under certain conditions maltodextrins can bind polar lipids, thereby altering their functional attributes [61, 62]. ITC has been used to examine the influence of solution conditions on the interactions between polar lipids (SDS) and maltodextrin, including the effects of changes in temperature, $\mathrm{pH}$, and salt concentration. The ITC measurements indicated that the enthalpy changes associated with surfactant demicellization were highly temperature dependent, going from endothermic at higher temperatures to exothermic at lower temperatures, which was attributed to the hydrophobic origin of this interaction. In contrast, the enthalpy changes associated with binding of surfactants to maltodextrin were always exothermic and much less sensitive to temperature, which was attributed to non-hydrophobic interactions. A minimum was observed for both the critical micelle concentration (CMC) of SDS and the apparent $\mathrm{CMC}\left(\mathrm{CMC}^{*}\right)$ of SDS in the presence of maltodextrin at intermediate temperatures; however, the temperature dependences of the $\mathrm{CMC}$ and $\mathrm{CMC}^{*}$ were quite small. There was no effect of $\mathrm{pH}$ on surfactant demicellization or binding to maltodextrin. On the other hand, salt concentration affected both of these parameters: there being a decrease of both $\mathrm{CMC}$ and $\mathrm{CMC}^{*}$ with increasing salt concentration and a maximum in the amount of surfactant bound to maltodextrin [63]. ITC has also been used to study interactions between SDS and maltodextrins with different molecular weights. The interaction between SDS and maltodextrins was exothermic, which was attributed to the incorporation of the hydrocarbon tail of the surfactant into a helical coil formed by the maltodextrin molecules. ITC measurements indicated that the number of SDS molecules bound per gram of maltodextrin increased with 
increasing maltodextrin molecular weight [64]. It is possible that surface active lipids (such as surfactants and bile salts) may interact with dietary maltodextrins in the GIT, which could alter their role in lipid digestion, transport, and absorption.

Bile salt-cyclodextrins interactions: Another class of carbohydrate-based food ingredients that may interact with surface-active lipids are cyclodextrins [65]. Cyclodextrins (CDs) have the ability to form complexes with a very wide range of ligands [66]. They are able to do this because they contain a hydrophobic cavity that can accommodate host molecules of specific sizes, shapes, and polarities [67-69]. For example, ITC has been used to study the characteristics of inclusion complexes of CDs with small molecule surfactants [70]. The non-polar linear chains of the surfactant molecules were incorporated into the hydrophobic cavities of the CD molecules. Three surfactants with the same non-polar tail $\left(\mathrm{C}_{12}\right)$ but different head-groups (anionic, cationic, or non-ionic) were studied. The effects of temperature, $\mathrm{pH}$, and salt concentration on the interactions were determined by ITC. The results showed that the ionic surfactants bound to CD much more strongly than the non-ionic ones. The enthalpy changes associated with binding of surfactants to $\mathrm{CD}$ were exothermic except for interactions measured at $50{ }^{\circ} \mathrm{C}$. There was no effect of $\mathrm{pH}$ on surfactant micellization or CD binding, whereas salt concentration affected surfactant micellization, but had little effect on the amount of surfactant bound to CD at saturation [70]. An improved understanding of the nature of the interactions between CDs and surface active lipids may lead to the development of functional ingredients with controlled behavior within the GIT.

Gastrointestinal component - pectin interactions: Several studies suggest that certain types of dietary fibers can inhibit lipid digestion and absorption in the small intestine $[10,14,15,71$ 73]. Increased consumption of dietary fiber may therefore be a suitable approach for reducing some of the adverse effects associated with consumption of high-fat diets. Pectin is a watersoluble dietary fiber widely in the food industry as a functional ingredient because of its waterholding, thickening, and gelling properties [74]. In vitro digestion studies have shown that pectin may decrease the rate and extent of lipid digestion by interacting with various components in the GIT $[71,73]$. Pectin may interact with bile salts and phospholipids in the small intestine, thereby altering the emulsification, digestion, solubilization and transport of lipids and their digestion products $[10,72]$. The binding of bile salts to pectin in the small intestine has also been proposed as one of the major mechanisms responsible for the ability of pectin to reduce cholesterol levels 
[75]. Pectin molecules may interfere with the reabsorption of bile salts in the small intestine, thereby reducing the amount of cholesterol absorbed and transported to the blood [75]. EspinalRuiz et al. (2014) evaluated the impact of pectin on the digestion of emulsified lipids and found that pectin reduced the extent of lipid digestion, which was attributed to its binding interactions with specific gastrointestinal components [76]. ITC experiments suggested that interactions of pectin with a solution containing a mixture of all the major gastrointestinal components (sodium, calcium, bile salts, and lipase) exhibited a large exothermic enthalpy change when the first few aliquots of the mixed GI tract fluids were injected into the reaction cell containing the pectin solution (Fig. 6). The enthalpy change became progressively less exothermic until it eventually reached a relatively low endothermic value at higher GIT levels. These results suggest that the pectin molecules interacted with some of the components in the GIT fluids, possibly through electrostatic interactions. ITC measurements were then carried out using pectin and specific GIT components to determine their potential interactions. In the case of calcium, the shape of the ITC curves suggested that there were several physicochemical events occurring sequentially, such as calcium ion binding, pectin conformational changes, and/or pectin aggregation [76]. The study of the binding of calcium ions to pectin may be important for fabricating novel functional foods that can control blood lipid levels. Calcium may interact with pectin in at least two different ways: $(i)$ pectin-calcium microgels may trap lipid droplets inside, thereby restricting the access of lipase to the lipid substrates [77] and, (ii) the formation of electrostatic complexes may prevent the calcium ions from forming insoluble soaps with long-chain free fatty acids at the lipid droplet surfaces, thereby preventing the lipase from functioning properly [78]. The ITC measurements indicated that the bile salts also interacted with the pectin molecules. In the absence of pectin there was a relatively large endothermic enthalpy change, which progressively decreased with increasing bile salt concentration [76]. This effect may have been due to the breakdown of bile salt micelles within the reaction chamber, resulting in the exposure of a greater number of nonpolar groups to water [56]. In the presence of pectin, there was a large endothermic peak followed by a value that was close to zero at higher bile salt concentrations. The large difference between these two curves suggested that there was an interaction between pectin and bile salts [79]. Likewise, the influence of lipase addition suggested a strong interaction between the lipase and the pectin. For this research, ITC experiments did still provide valuable information because they indicated that one or more types of interaction are taking place between two molecules. This 
latter may have important implications for understanding the influence of pectin on lipid digestion. In particular, calcium ions and bile salts appear to promote the formation of pectin microgels that can lead to flocculation of lipid droplets in the gastrointestinal tract, decreasing the ability of emulsified lipids to be accessed by gastrointestinal lipases and thereby inhibiting digestion [76].

\subsection{Interactions involving proteins}

Many foods contain proteins as well as lipids, and these proteins may impact lipid bioavailability through various mechanisms. In addition, there are various types of proteins in the human GIT itself that can interact with the lipids, such as digestive enzymes. Consequently, it is important to elucidate how proteins behave within the GIT. In this section, the use of ITC for studying interactions between proteins and other molecular species that may be present within the GIT are discussed.

Protein-tannin interactions: Tannins are polyphenolic phytochemicals that are found in a variety of different food and beverage products. Protein-tannin interactions may promote aggregation of food proteins, which could alter their digestibility by proteases within the GIT. In addition, tannins may interact with digestive enzymes (such as amylases, lipases, or proteases) in the GIT and alter their enzymatic activity. Consequently, it is useful to study the influence of specific tannins on the behavior of specific food proteins and digestive enzymes. ITC has been used to study interactions between tannins and proteins [80,81]. These studies have shown that multiple tannin molecules can bind to a single protein molecule, and that the binding was a combination of a major exothermic and a minor endothermic interaction giving a biphasic ITC titration curve [82]. Another study on the astringency of tannins isolated from grapes and wines used ITC to detect the binding of tannin to polyproline, which was used as a model of prolinerich salivary proteins [83]. This study also observed a biphasic ITC titration curve. The minor endothermic interaction was temperature dependent indicating a change in $\Delta C_{p}$ associated with hydrophobic interactions, whereas the major exothermic interaction was unaffected by temperature (indicating it was probably due to hydrogen bonding). Both interactions did vary with ageing of the tannins, which was associated with tannin complex formation [83]. ITC has been used to study interactions between salivary proteins and tannins that may lead to astringency [84]. This study showed that the interactions may occur in three-stages with 
increasing protein concentration: (i) binding of proteins to tannins until saturation occurs; (ii) formation of metastable colloidal particles; (iii) aggregation of colloidal particles.

Protein-chitosan interactions: Chitosan is a cationic polysaccharide that may impact lipid digestion due to its ability to interact with bile salts, phospholipids, and free fatty acids. Consequently, any other food component that can bind to chitosan within the GIT may change its ability to influence lipid digestion. ITC has been used to study the interactions between chitosan and a globular protein ( $\beta$-lactoglobulin) at different $\mathrm{pH}$ values (3-7) [85]. This study showed that there was an exothermic interaction between chitosan and $\beta$-lactoglobulin at $\mathrm{pH} 5$ to 7 , where the two biopolymers had opposite charges. At pH 6, about one $\beta$-lactoglobulin molecule bound per six chitosan sugar units at saturation [85].

E-polylysine-polysaccharide interactions: The cationic polypeptide $\varepsilon$-polylysine ( $\varepsilon$-PL) is a potent food-grade antimicrobial against various pathogens and spoilage microorganisms. Nevertheless, its highly cationic nature means that it may interact with anionic components in food products and alter their functionality [86]. In particular, it may interact with anionic bile salts, phospholipids, or free fatty acids in the GIT, and therefore alter lipid bioavailability. Chang and co-workers (2014) examined the interactions of $\varepsilon$-PL with various kinds of foodgrade polysaccharides: anionic (carrageenan, alginate and pectin), neutral (dextran), and cationic (chitosan) [87]. The ITC experiments showed that the interaction of $\varepsilon$-PL with dextran and chitosan was relatively weak because there was no electrostatic attraction involved [87] (Fig. 7). Conversely, the ITC titration curves indicated that cationic $\varepsilon$-PL interacted strongly with anionic polysaccharides (such as carrageenan, pectin, and alginate), which was attributed to strong electrostatic attraction between the oppositely charged components. Fig. 7 indicates that understanding interactions between biopolymers is important for describing the gastrointestinal fate of many foods. The general shape of the enthalpy versus $\varepsilon$-PL concentration profiles depended on the nature of the anionic polysaccharides used. The ITC profiles were fairly similar for alginate and carrageenan, which are both linear anionic polysaccharides with relatively high linear charge densities. On the other hand, the ITC profiles for the pectin were appreciably different from that of alginate and carrageenan, which was attributed to the fact that they had a lower charge density and were branched molecules. 


\subsection{Limitations of ITC}

One of the major limitations in using ITC to understand complex systems is that it is often difficult to identity the precise molecular origin of any observed enthalpy changes. Exothermic or endothermic reactions associated with molecular interactions may arise due to molecular events such as dilution, micelle formation/dissociation, conformational changes, aggregation, phase transitions, or binding phenomenon. For this reason, it is often advantageous to use ITC in combination with other analytical methods that can provide information about these events. For example, light scattering methods can be used to provide information about aggregate formation, spectroscopy methods can be used to provide insights into conformational changes, and ion selective electrodes can provide information about changes in ion binding.

\section{Conclusions/Summary}

ITC is an extremely powerful tool for characterizing molecular interactions in food systems, and can provide valuable information about many types of physicochemical phenomena involving food components such as proteins, carbohydrates, lipids, surfactants, and minerals. For systems at equilibrium, ITC can provide fundamental thermodynamic parameters (such as binding constants, number of binding sites, and free energy, enthalpy, and entropy changes) that can be used to establish the physiochemical origin of molecular interactions. In this article, we have focused on applications of ITC for understanding the molecular interactions that may occur within the human gastrointestinal tract, and their potential impact on the bioavailability of lipids. ITC has been used to study the micellization of surface active lipids (surfactants and bile salts) and the factors that impact this process. It has also be used to understand the binding interactions between various types of food component, such as lipids, proteins, carbohydrates, and surfactants. In addition, based on applications of ITC in other fields it may be utilized to study the factors that influence enzymatic hydrolysis reactions, such as lipid, protein, or carbohydrate digestion. The results obtained from ITC experiments may facilitate the rational design and development of novel functional food products designed to increase human health and wellbeing. The authors believe that ITC will find increasing utilization within food science to understand the major factors impacting the gastrointestinal fate of foods. Nevertheless, like many other analytical instruments, ITC is most suitable for studying relatively simple well-defined systems due to the difficulties in interpreting the enthalpy changes associated with complex 
multicomponent systems. Despite this limitation, it can still provide useful insights into the most important physicochemical factors influencing the gastrointestinal fate of specific food components.

\section{Corresponding Authors}

*Phone: +1 (413) 5451019. E-mail: mcclements@foodsci.umass.edu (David Julian

McClements). E-mail: iarroyo@foodsci.umass.edu (Izlia Arroyo-Maya).

\section{Notes}

The authors declare no competing financial interest.

\section{Acknowledgments}

This material was partly based upon work supported by the Cooperative State Research, Extension, Education Service, USDA, Massachusetts Agricultural Experiment Station (Project No. 831) and USDA, NRI Grants (2011-03539, 2013-03795, 2011-67021, and 2014-67021). I. A.-M. thanks the CONACYT, Mexico (Registration no 208139) for financial support.

\section{References}

[1] D.J. McClements, E.A. Decker, Y. Park, J. Weiss, Structural design principles for delivery of bioactive components in nutraceuticals and functional foods, Critical reviews in food science and nutrition, 49 (2009) 577-606.

[2] D.J. McClements, E.A. Decker, J. Weiss, Emulsion-based delivery systems for lipophilic bioactive components, Journal of food science, 72 (2007) R109-124.

[3] D.J. McClements, Decker, E.A., and Park, Y., Physicochemical and structural aspects of lipid digestion. , In: Understanding and Controlling the

Microstructure of Complex Foods, McClements, D.J., Ed., CRC

Press, Boca Raton, FL. (2007) pp. 483-503.

[4] K.J. Yeum, R.M. Russell, Carotenoid bioavailability and bioconversion, Annual review of nutrition, 22 (2002) 483-504.

[5] G. Kossena, Boyd, B., Porter, C., Charman, W., Separation and Characterization of the Colloidal Phases 
Produced on Digestion of Common Formulation Lipids

and Assessment of Their Impact on the Apparent Solubility

of Selected Poorly Water-Soluble Drugs, Journal of Pharmaceutical Sciences, 92 (2002).

[6] H.C.F.a.R.M. Clark, <Intestinal absortion and tissue distribution of carotenoids.pdf>, Nutritional Biochemistry, 8 (1997) 364-377.

[7] E. Fernandez-Garcia, I. Carvajal-Lerida, A. Perez-Galvez, In vitro bioaccessibility assessment as a prediction tool of nutritional efficiency, Nutrition research, 29 (2009) 751-760.

[8] C. Versantvoort, van de Kamp, E., Rompelberg, C., $<$ Development and applicability of an in vitro digestion model in assessing the bioaccessibility of contaminants from food.pdf $>$, RIVM report 320102002, (2004).

[9] B. Holst, G. Williamson, Nutrients and phytochemicals: from bioavailability to bioefficacy beyond antioxidants, Current opinion in biotechnology, 19 (2008) 73-82.

[10] D.J. McClements, Y. Li, Review of in vitro digestion models for rapid screening of emulsion-based systems, Food \& function, 1 (2010) 32-59.

[11] A.M.1. Niels Hønberg Zangenberga, Henning Gjelstrup Kristensena, Lars Hovgaarda, $<$ A dynamic in vitro lipolysis model 1 controlling the rate of lipopysis by continous addition of calcium.pdf $>$, European Journa of Pharmaceutical Sciences, 14 (2001) 115-122.

[12] P. Reis, K. Holmberg, H. Watzke, M.E. Leser, R. Miller, Lipases at interfaces: a review, Advances in colloid and interface science, 147-148 (2009) 237-250.

[13] P. Reis, R. Miller, J. Kragel, M.E. Leser, V.B. Fainerman, H. Watzke, K. Holmberg, Lipases at interfaces: Uniques interfacial properties as globular proteins, Langmuir, 24 (2008) 6812-6819.

[14] D.J. McClements, Y. Li, Structured emulsion-based delivery systems: controlling the digestion and release of lipophilic food components, Advances in colloid and interface science, 159 (2010) 213-228.

[15] S. Mun, E.A. Decker, Y. Park, J. Weiss, D.J. McClements, Influence of Interfacial Composition on in Vitro Digestibility of Emulsified Lipids: Potential Mechanism for Chitosan's Ability to Inhibit Fat Digestion, Food Biophysics, 1 (2006) 21-29.

[16] W.H. De Jong, W.I. Hagens, P. Krystek, M.C. Burger, A.J. Sips, R.E. Geertsma, Particle size-dependent organ distribution of gold nanoparticles after intravenous administration, Biomaterials, 29 (2008) 1912-1919.

[17] G.A. van Aken, Modelling texture perception by soft epithelial surfaces, Soft Matter, 6 (2010) 826.

[18] F. Kong, R.P. Singh, Disintegration of solid foods in human stomach, Journal of food science, 73 (2008) R67-80.

[19] M.J. Ferrua, R.P. Singh, Modeling the fluid dynamics in a human stomach to gain insight of food digestion, Journal of food science, 75 (2010) R151-162.

[20] E. Roger, Lagarce, F., Garcion, E., and Benoit, J.P., Biopharmaceutical

parameters to consider in order to alter the fate of nanocarriers after oral 
delivery., Nanomedicine, 5 (2010) 287-306.

[21] L.R. Johnson, Gastrointestinal Physiology, 6th Edition. Mosby, St.

Louis, Missouri., (2001).

[22] D.J. McClements, E.A. Decker, Y. Park, Physicochemical and structural aspects of lipid digestion. , in: D.J. McClements (Ed.) In: Understanding and Controlling the Microstructure of Complex Foods, CRC Press, , Boca Raton, FL., 2007, pp. 483-503.

[23] R. Ghai, R.J. Falconer, B.M. Collins, Applications of isothermal titration calorimetry in pure and applied research--survey of the literature from 2010, Journal of molecular recognition : JMR, 25 (2012) 32-52.

[24] A. Cooper., Microcalorimetry of protein-protein interactions., Methods Mol. Biol., 88 (1998) 11-22.

[25] O.H. Velazquez-Campoy A, Nezami A, Muzammil S, Freire E., Isothermal titration calorimetry., Curr. Protoc Cell Biol. Chapter

17: 17-8., (2004).

[26] J.B.F.N.E. Koos Bijma, Michael J. Blandamer, Paul M. Cullis, Philip M. Last, Keith D. Irlam and L. Giorgio Soldi <Classification of calorimetric titration plots for alkyltrimethylammonium and alkylpyridinium cationic surfactants in aqueos solutions.pdf $>$, J. Chem. Soc., Faraday T rans., 93 (1997) 1579-1584.

[27] R.J.M.a.T.A. Hatton, <Enthalpy Measurements in aqueous SDS:DTAB solutions using isothermal titration calorimetry.pdf $>$, Langmuir, 14 (1998) 4081-4087.

[28] V.V. Ornella Ortona, Luigi Paduano, and Lucia Costantino, $<$ Microcalorimetry study of some short-chain nonionic surfactants.pdf $>$, Journal of Colloid and Interface Science, 203 (1998) 477-484.

[29] S.K. Singh, Nilsson, S., , <Thermodynamics of interaction between some cellulose ethers and SDS by titration microcalorimetry.pdf $>$, Journal of Colloid and Interface Science, 213 (1999) 133-155.

[30] J.F.L.v.B. Jan Kevelam, Wilfried Blokzijl, and Jan B. F. N. Engberts, $<$ Polymer-surfactant interactions studied by titration calorimetry influence of polymer hydrophobicity, electrostatic forces, and surfactant aggregational state.pdf $>$, Langmuir, 12 (1996) 4707-4717.

[31] G.A.F. S. M. Ghoreishi, D. M. Bloor, J. F. Holzwarth, and E. Wyn-Jones, EMMF and microcalorimetry studies associates with the binding of the cationic surfactants to neutral polymers, Langmuir, 15 (1999) 5474-5479.

[32] D.G. Arie Derksen, and Donald M. Small, $<$ Calorimetry of apolipoprotein-A1 binding to phosphatidylcholine-triolein-cholesterol emulsions.pdf>, Biophysical Journal, 70 (1996) 330338.

[33] M. Okubo, Suzuki, T., Sakauchi, A., $<$ Microanalysis of the surface concentration of sulfate groups at polystyrene particle by isothermal titration calorimetry.pdf $>$, Colloid \& Polymer Science, 277 (1999) 579-582. 
[34] R.P. Geng Wang, Ju Zhang, <Sodium dodecyl sulfate binding to poly(Nisopropylacrylamide) microgel latex studied by isothermal titration calorimetry.pdf $>$, Colloid and Surfaces A: Physicochemical and Engineering Aspects, 153 (1999) 335-340.

[35] E. Opatowski, M.M. Koziov, D. Lichtenberg, <Partitioning of octyl glucoside between cotyl glucodide:phosphatidylcholine mixed aggregates.pdf>, Biophysical Journal, 73 (1997) 14481448 .

[36] W.C. W. Eli, Q. Xue, J., The association of anionic surfactants with $\beta$-cyclodextrin. An isothermal titration calorimeter study, Chem. Therm., 31 (1999).

[37] C. Aguirre, I. Condado-Morales, L.F. Olguin, M. Costas, Isothermal titration calorimetry determination of individual rate constants of trypsin catalytic activity, Analytical Biochemistry, 479 (2015) 18-27.

[38] K. Maximova, J. Trylska, Kinetics of trypsin-catalyzed hydrolysis determined by isothermal titration calorimetry, Analytical Biochemistry, 486 (2015) 24-34.

[39] M.K. Transtrum, L.D. Hansen, C. Quinn, Enzyme kinetics determined by single-injection isothermal titration calorimetry, Methods, 76 (2015) 194-200.

[40] P. Garidel, Hildebrand, A., R. Neubert, R., and Blume, A., Thermodynamic characteriation of bile salt aggregation as a function of temperature and ionic strength using isothermal titration calorimetry, Langmuir, 16 (2000) 5267-5275.

[41] A. Jover, Meijide, F., Rodri'guez Nu'ñ ez, E., Va'zquez Tato, J., and Mosquera, M., $<$ Aggregation number for sodium deoxycholate from steady-state and time-resolved fluorescence.pdf>, Langmuir, 13 (1997) 3590-3590.

[42] P. Mukerjee, Micellar properties of drugs: Micellar and nonmicellar patterns of selfassociation of hydrophobic solutes of different molecular structures - monomer fraction, availability, and misuses of micellar hypothesis, Pharmaceutical Sciences, 63 (1974) 972-981.

[43] S. Paula, Siis, W., Tuchtenhagen, J., and Blume, A., <Thermodynamics of micelle formation as a function of temperature a high sesitive titration calorimetry study.pdf $>$, J. Phys. Chem., 99 (1995) 11742-11751.

[44] P. Garidel, and Blume, A., Interaction of alkaline earth cations with negatively charged phospholipid 1,2-dimyristoyl-sn-glycero-3-phosphoglycerol, Langmuir, 15 (1999) 5526-5534.

[45] P. Becher, Basic theory, measurement and applications, in: Encyclopedia of Emulsion Technology, vol. 2, Marcel

Dekker, New York., (1985).

[46] L.L. Schramm., Emulsions: Fundamentals and Applications

in the Petroleum Industry., American Chemical Society, Washington, DC., (1992).

[47] D.J. McClements, Food Emulsions: Principles, Practice and Techniques., Third Edition ed., CRC Press, Boca Raton, FL, 2015.

[48] R. Pal, P. Becher (Ed.), Encyclopedia of Emulsion Technology, vol. 4, Marcel Dekker, New York., (1996). 
[49] D.J.M. Ratjika Chanamai, <Isothermal titration calorimetry measurement of enthalpy changes in monodisperse oil in water emulsions undergoing depletion flocculation.pdf>, Colloids and Surfaces A, 181 (2001) 261-269.

[50] M. Benko, L.A. Kiraly, S. Puskas, Z. Kiraly, Complexation of beta-Cyclodextrin with a Gemini Surfactant Studied by Isothermal Titration Microcalorimetry and Surface Tensiometry, Langmuir, 30 (2014) 6756-6762.

[51] E. Wumanjiang, W.H. Chen, W. Chen, Q.J. Xue, The association of Triton X series surfactants with beta-cyclodextrin - An isothermal titration calorimetric study, Acta Chimica Sinica, 58 (2000) 127-130.

[52] L. Chiappisi, D.C. Li, N.J. Wagner, M. Gradzielski, An improved method for analyzing isothermal titration calorimetry data from oppositely charged surfactant polyelectrolyte mixtures, Journal of Chemical Thermodynamics, 68 (2014) 48-52.

[53] S.D. Clas, Quaternized colestipol, an improved bile salt adsorbent: In vitro studies., Journal of Pharmaceutical Science, 80 (1991) 128-131.

[54] K.J. Lee, Kim, S. U., \& Kim, J. H., Modification of chitosan to improve its hypocholesterolemic capacity., Bioscience Biotechnology and Biochemistry, 63 (1999) 833-839.

[55] J.A. Monro, Lee, J., \& Sinclair, B. R., Bile acid activity in the presence of dietary fibres, casein, calcium, phospholipid, fatty acid and cholesterol: Factorial experiments in vitro., Food Chemistry, 44 (1992) 325-329.

[56] M. Thongngam, D.J. McClements, Isothermal titration calorimetry study of the interactions between chitosan and a bile salt (sodium taurocholate), Food Hydrocolloids, 19 (2005) 813-819.

[57] J.F. Kennedy, Knill, C. L., \& Taylor, D. W., Maltodextrins., In M. W. Kearsley, \& S. Z. Dziedzic (Eds.), Handbook of starch hydrolysis products and their derivatives. Cambridge, UK: Blackie Academic and Professional. Chapter 3., (1995).

[58] I.S. Chronakis, On the molecular characteristics, compositional properties, and structuralfunctional mechanisms of maltodextrins: A review., Critical reviews in food science and nutrition, 38 (1998) 599-637.

[59] Y.J. Wang, \& Wang, L., Structures and properties of commercial maltodextrins from corn, potato, and rice starches., Starch, (2000) 296-304.

[60] C.G. Biliaderis, Swan, R. S., \& Arvanitoyannis, I., Physicochemical properties of commercial starch hydrolyzates in the frozen state., Food Chemistry, 64 (1999) 537-546.

[61] J. Merta, \& Stenius, P., Interactions between cationic starch and anionic surfactants 1. Phase equilibria and surface tensions., Colloids Polymer Science, 273 (1995) 974-983.

[62] M.G. Semenova, Belyakova, L. E., Antipova, A. S., Polikarpov, Y. N., Klouda, L., Markovic, A., Effect of maltodextrins on the surface activity of small molecules surfactants, Colloids and Surfaces B: Biointerfaces, 31 (2003) 47-54.

[63] A. Wangsakan, Chinachoti, P., \& McClements, D. J., Isothermal titration calorimetry study of the influence of temperature, $\mathrm{pH}$ and salt on maltodextrin-anionic surfactant interactions, Food Hydrocolloids, 20 (2006) 461-467. 
[64] A. Wangsakan, Chinachoti, P., \& McClements D. J., Effect of different dextrose equivalent of maltodextrin on the interactions with anioinc surfactant in an isothermal titration calorimetry study, Journal of Agriculture and Food Chemistry, 51 (2003) 7810-7814.

[65] K. Fujii, Takata, H., Yanase, M., Terada, Y., Ohdan, K., Takaha, T, Bioengineering and application of novel glucose polymers., Biocatalysis and Biotransformation, 21 (2003) 167-172.

[66] E.M.M. Del Valle, Cyclodextrins and their uses: A review., Process Biochemistry, 39 (2004) 1033-1046.

[67] S. Kitamura, Nakatani, K., Takaha, T., \& Okada, S., Complex formation of large-ring cyclodextrins with iodine in aqueous solution as revealed by isothermal titration calorimetry., Macromolecular Rapid Communications, 20 (1999) 612-615.

[68] K. Tomono, Mugishima, A., Suzuki, T., Goto, H., Ueda, H., Nagai, T., Interaction between cycloamylose and various drugs., Journal of Inclusion Phenomena and Macrocyclic Chemistry, 44 (2002) 53-56.

[69] H. Ueda, Physicochemical properties and complex formation abilities of large-ring cyclodextrins., Journal of Inclusion Phenomena and Macrocyclic Chemistry, 44 (2002) 53-56.

[70] S. Mun, S.-J. Rho, Y.-R. Kim, Study of inclusion complexes of cycloamylose with surfactants by isothermal titration calorimetry, Carbohydrate Polymers, 77 (2009) 223-230.

[71] P. Gunness, M.J. Gidley, Mechanisms underlying the cholesterol-lowering properties of soluble dietary fibre polysaccharides, Food \& function, 1 (2010) 149-155.

[72] S.J. Hur, B.O. Lim, E.A. Decker, D.J. McClements, In vitro human digestion models for food applications, Food Chemistry, 125 (2011) 1-12.

[73] Y. Li, D.J. McClements, Modulating lipid droplet intestinal lipolysis by electrostatic complexation with anionic polysaccharides: Influence of cosurfactants, Food Hydrocolloids, 35 (2014) 367-374.

[74] B.R. Thakur, R.K. Singh, A.K. Handa, Chemistry and uses of pectin--a review, Critical reviews in food science and nutrition, 37 (1997) 47-73.

[75] L.W.D. Philip E. Pfeffer, Peter D. Hoagland, and George G. McDonald, <Molecular interactions with dietary fiber components Investigation of the possible association of pectin and bile acids.pdf $>$, J. Agric. Food Chem., 29 (1981) 455-461.

[76] M. Espinal-Ruiz, F. Parada-Alfonso, L.P. Restrepo-Sanchez, C.E. Narvaez-Cuenca, D.J. McClements, Interaction of a dietary fiber (pectin) with gastrointestinal components (bile salts, calcium, and lipase): a calorimetry, electrophoresis, and turbidity study, Journal of agricultural and food chemistry, 62 (2014) 12620-12630.

[77] O.K. Simo, Y. Mao, T. Tokle, E.A. Decker, D.J. McClements, Novel strategies for fabricating reduced fat foods: Heteroaggregation of lipid droplets with polysaccharides, Food Research International, 48 (2012) 337-345.

[78] A. Ye, J. Cui, X. Zhu, H. Singh, Effect of calcium on the kinetics of free fatty acid release during in vitro lipid digestion in model emulsions, Food Chem, 139 (2013) 681-688. 
[79] A. Wangsakan, P. Chinachoti, D.J. McClements, Isothermal titration calorimetry study of the influence of temperature, $\mathrm{pH}$ and salt on maltodextrin-anionic surfactant interactions, Food Hydrocolloids, 20 (2006) 461-467.

[80] P.A. Frazier RA, Green RJ., Isothermal titration calorimetry

study of epicatechin binding to serum albumin., in: J.

Pharmaceut Biomed., vol. 41, 2006, pp. 1602-1605.

[81] G.C. Poncet-Legrand C, Cheynier V, Imberty A., Interactions between flavan-3-ols and poly(L-proline) studied by isothermal titration calorimetry: effect of the tannin structure., J. Agr. Food Chem., (2007) 9235-9240.

[82] D.E. Frazier RA, Green RJ, Stringano E, Willoughby I,, M.-H.I. Plant J, Interactions of tea tannins and condensed tannins with proteins., J. Pharmaceut. Biomed., 51 (2010) 490-495.

[83] F.R. McRae JM, Kennedy JA., Thermodynamics of grape and wine tannin interaction with polyproline: implications for red wine astringency., J. Agric. Food Chem., 58 (2010) 1251012518.

[84] C. Pascal, C. Poncet-Legrand, A. Imberty, C. Gautier, P. Sarni-Manchado, V. Cheynier, A. Vernhet, Interactions between a non glycosylated human proline-rich protein and flavan-3-ols are affected by protein concentration and polyphenol/protein ratio, Journal of agricultural and food chemistry, 55 (2007) 4895-4901.

[85] D. Guzey, D.J. McClements, Characterization of $\beta$-lactoglobulin-chitosan interactions in aqueous solutions: A calorimetry, light scattering, electrophoretic mobility and solubility study, Food Hydrocolloids, 20 (2006) 124-131.

[86] Y. Chang, L. McLandsborough, D.J. McClements, Interactions of a cationic antimicrobial (epsilon-polylysine) with an anionic biopolymer (pectin): an isothermal titration calorimetry, microelectrophoresis, and turbidity study, Journal of agricultural and food chemistry, 59 (2011) 5579-5588.

[87] Y. Chang, L. McLandsborough, D.J. McClements, Interaction of cationic antimicrobial ( $\varepsilon$ polylysine) with food-grade biopolymers: Dextran, chitosan, carrageenan, alginate, and pectin, Food Research International, 64 (2014) 396-401. 
Table 1. Some lipophilic bioactive compounds that may be incorporated into foods and

\begin{tabular}{|c|c|c|}
\hline Name & Types & $\begin{array}{c}\text { Potential nutritional } \\
\text { benefits }\end{array}$ \\
\hline Fatty acids & $\begin{array}{l}\omega-3 \text { fatty acids, conjugated } \\
\text { linoleic acid, butyric acid }\end{array}$ & $\begin{array}{l}\text { Heart disease, cancer, bone } \\
\text { health, immune response } \\
\text { disorders, weight gain, } \\
\text { stroke prevention, mental } \\
\text { health, visual acuity }\end{array}$ \\
\hline Carotenoids & $\begin{array}{l}\beta \text {-carotene, lycopene, lutein, } \\
\text { zeaxanthin, }\end{array}$ & $\begin{array}{l}\text { Heart disease, cancer, } \\
\text { macular degeneration, } \\
\text { cataracts, }\end{array}$ \\
\hline Oil-soluble antioxidants & $\begin{array}{l}\text { Tocopherols, flavonoids, } \\
\text { polyphenols, }\end{array}$ & Heart disease, cancer, \\
\hline Phytosterols & $\begin{array}{l}\text { Stigmasterol, } \quad \beta \text {-sitosterol, } \\
\text { and campesterol }\end{array}$ & Coronary heart disease \\
\hline Oil-soluble vitamins & Vitamin A, D & $\begin{array}{l}\text { Eye health, bone health, } \\
\text { cancer }\end{array}$ \\
\hline Nutraceuticals & Co-enzyme Q & $\begin{array}{l}\text { Hypertension, hearth } \\
\text { disease, diabetes, cancer }\end{array}$ \\
\hline
\end{tabular}

beverages, and some of the health claims made for them (McClements et al., 2010). 


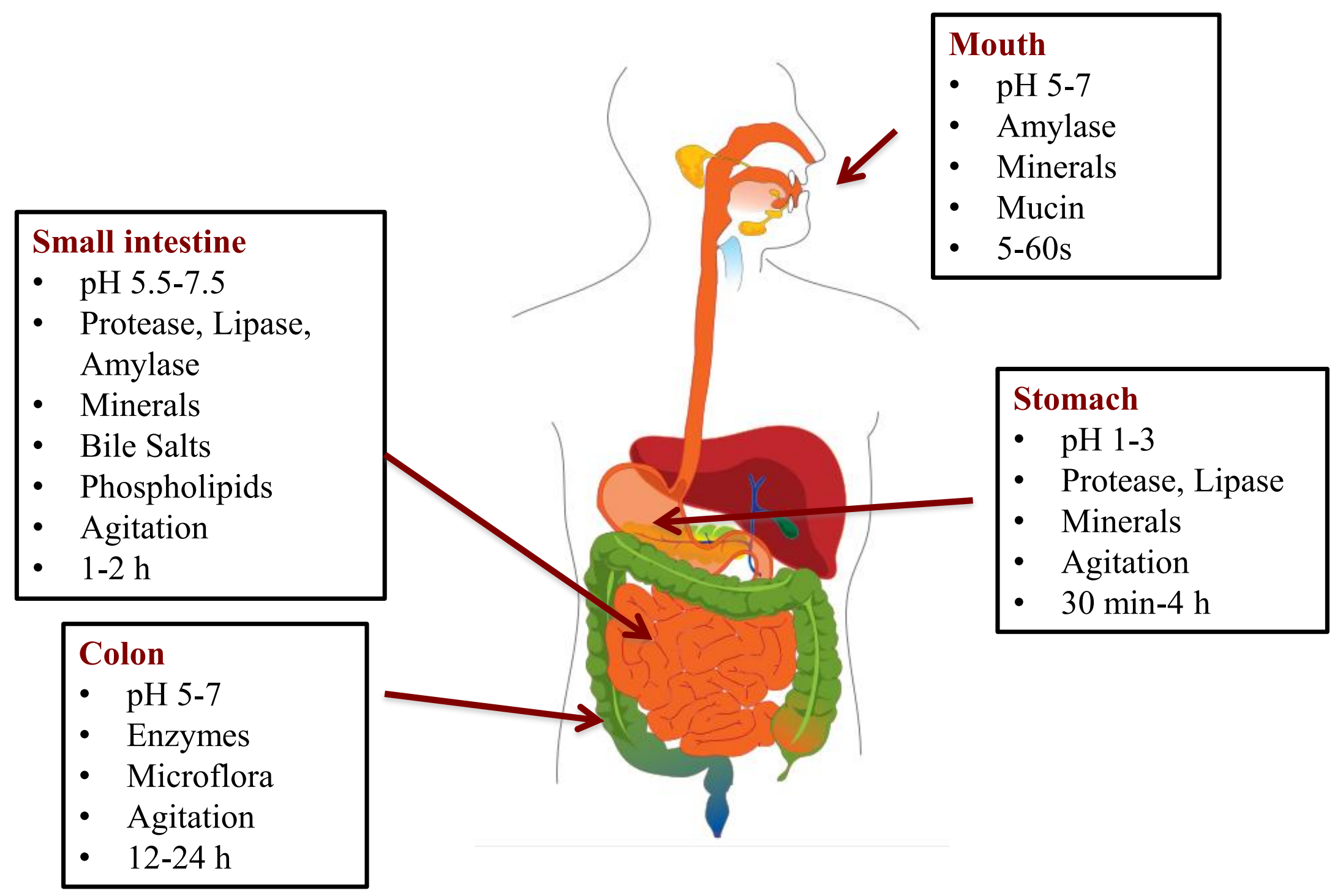

Fig. 1. Schematic diagram of the complex physicochemical and physiological processes that may occur during lipid digestion and absorption of emulsified lipids in the human GIT. 


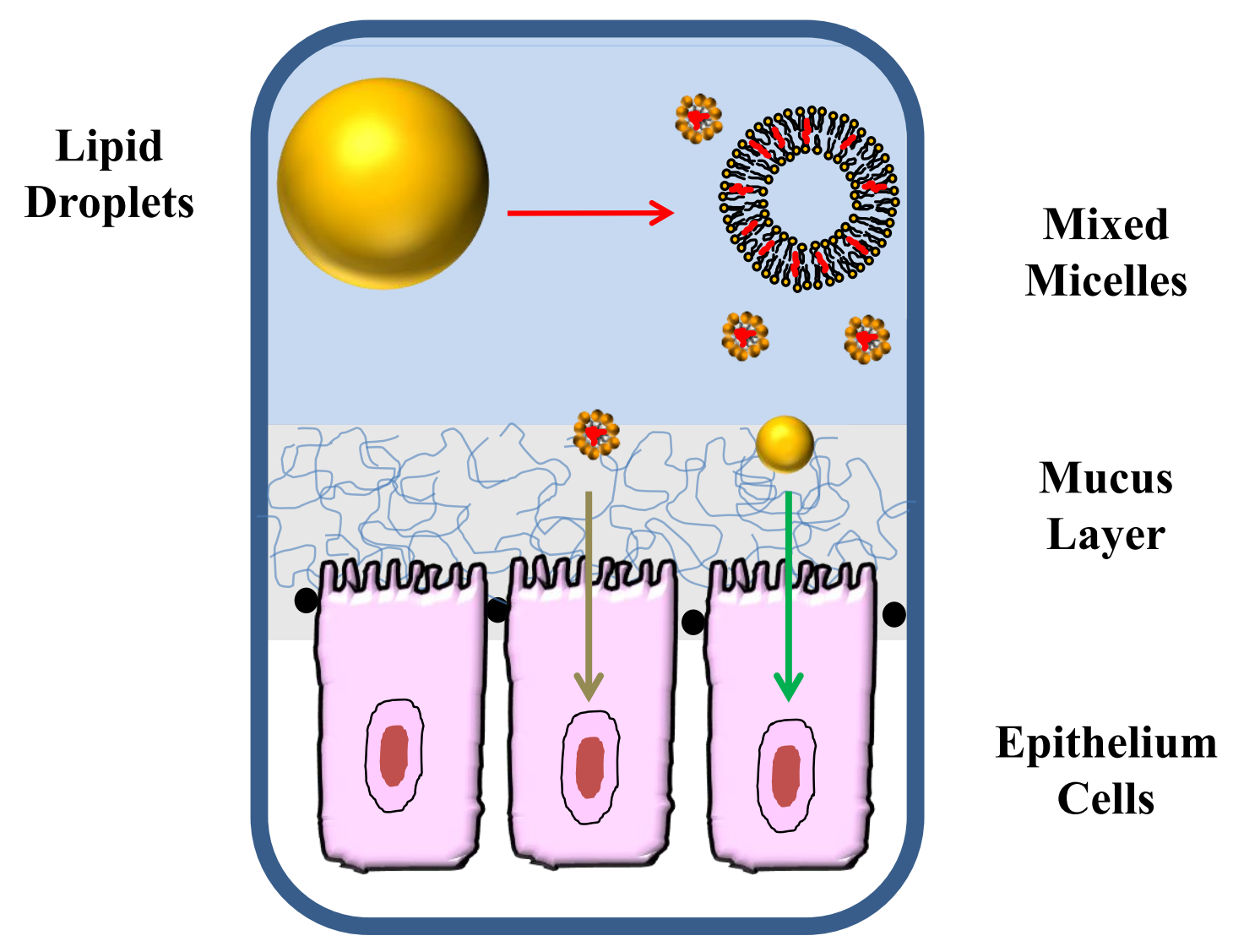

Fig. 2. Lipid absorption within the human GIT of the lipid droplets and any functional components encapsulated within these particles. The lipid droplets are digested by lipases and form mixed micelles that are transported through the mucus layer to the epithelium cells where they may be absorbed by active or passive transport mechanisms. 

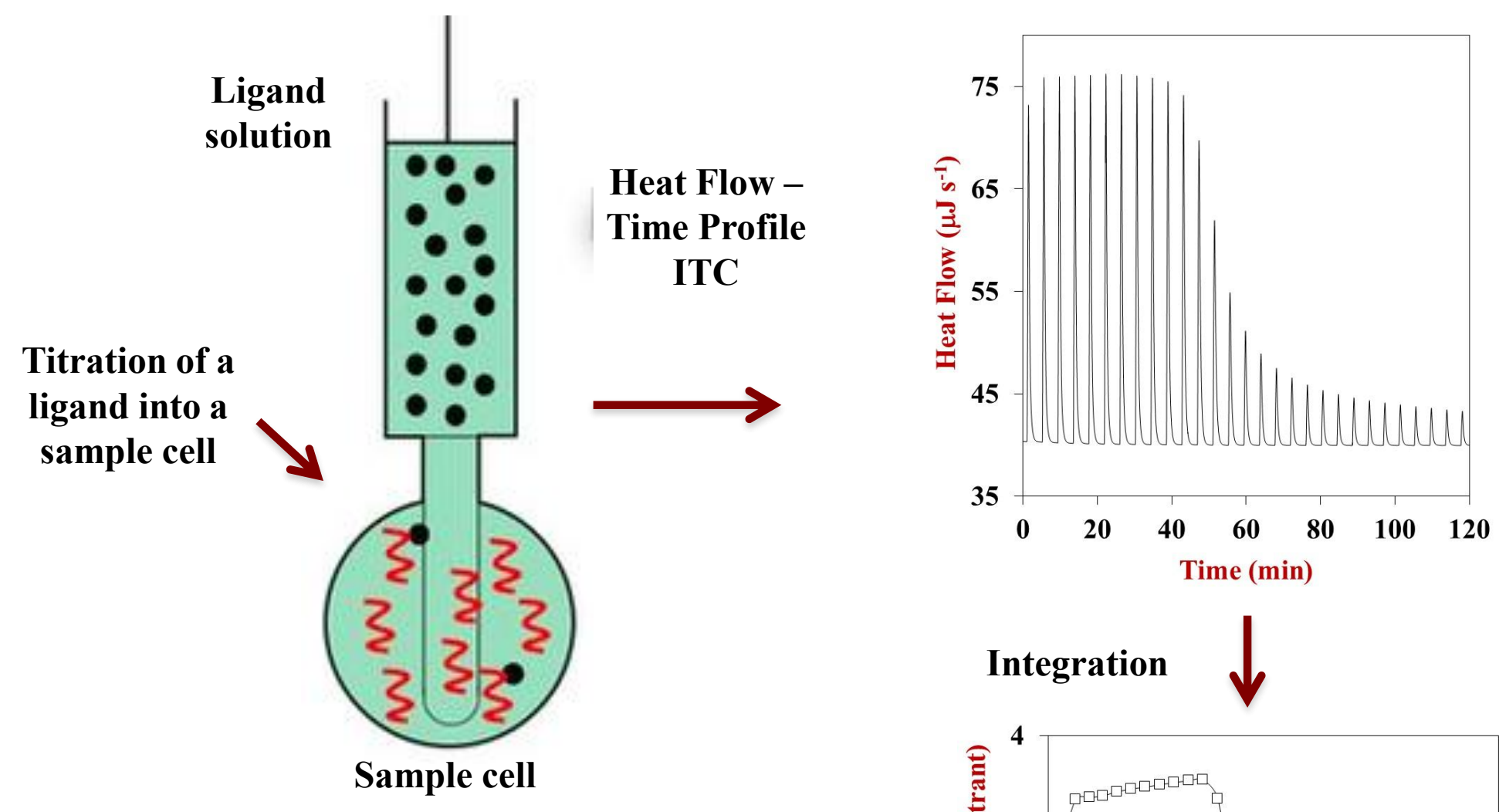

Fig. 3. Schematic diagram of data obtained from an ITC experiment when a ligand is titrated into a sample.

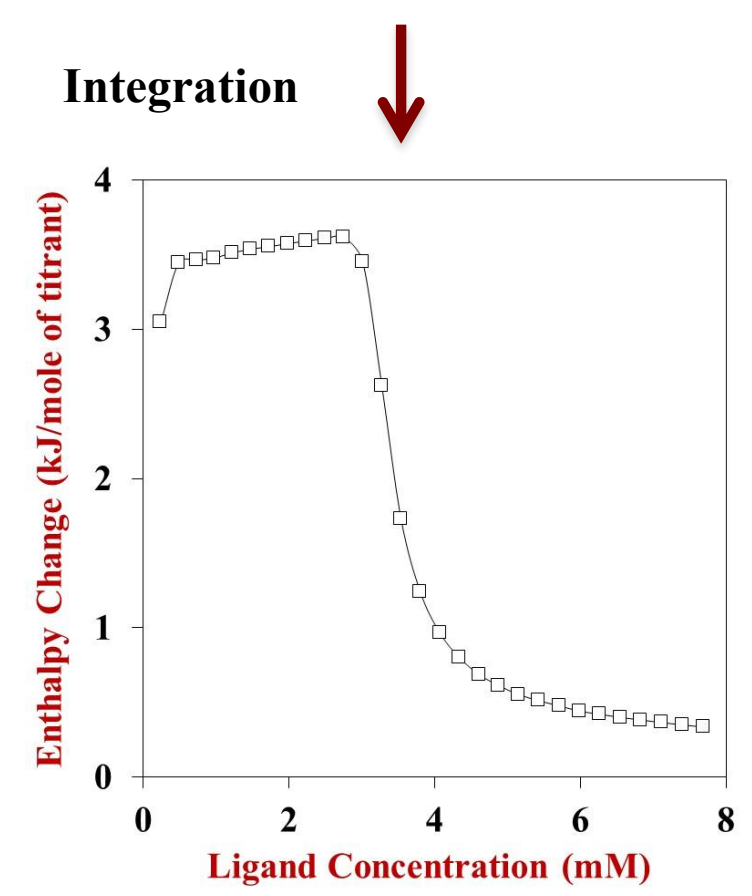




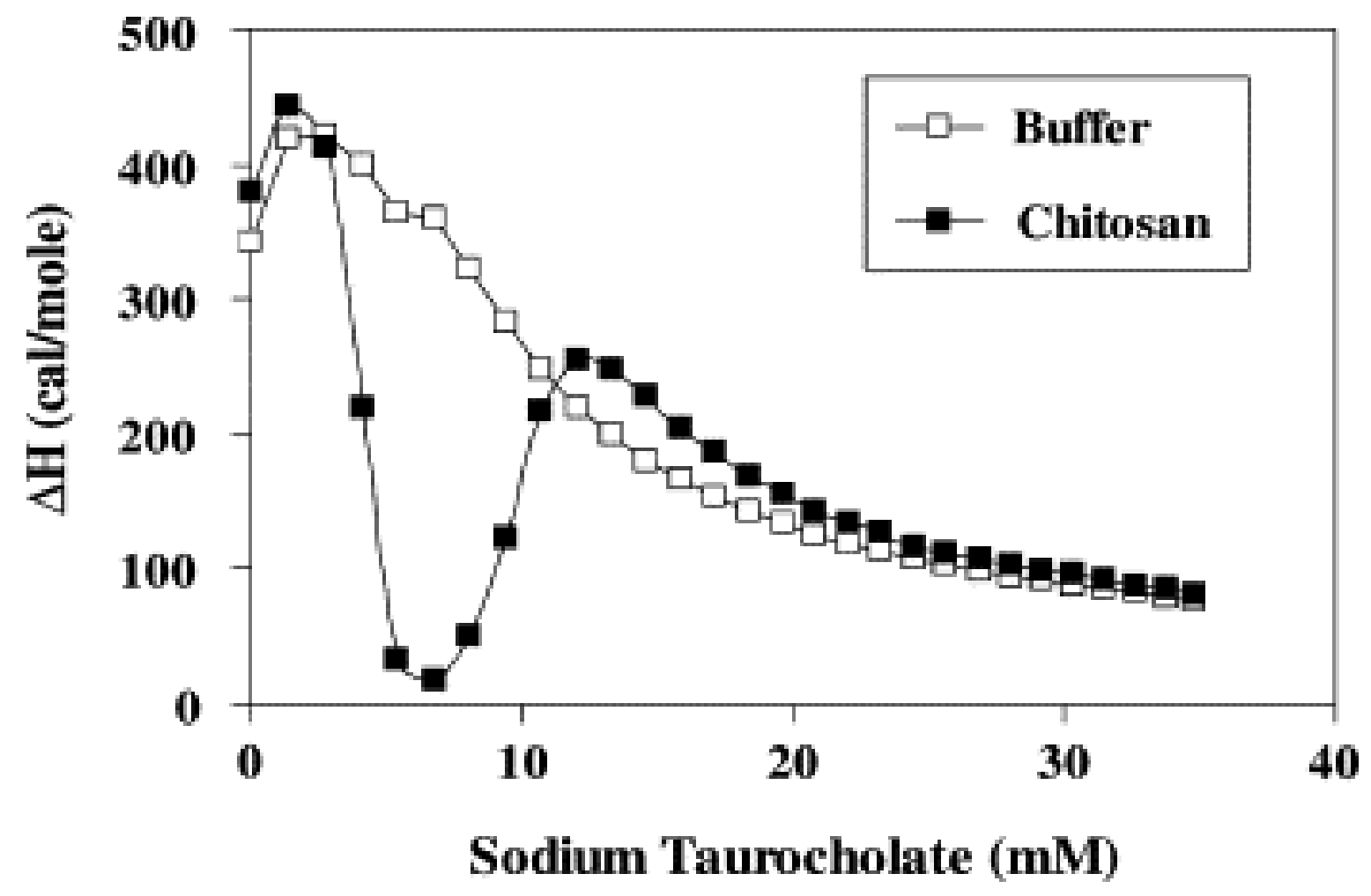

Fig. 4. Enthalpy change when sodium taurocholate $(200 \mathrm{mM})$ is injected into acetate buffer containing: 0 and $0.1 \mathrm{wt} \%$ chitosan $\left(\mathrm{pH} 3,30^{\circ} \mathrm{C}\right)$. Data from Thongngam and McClements (2005). 

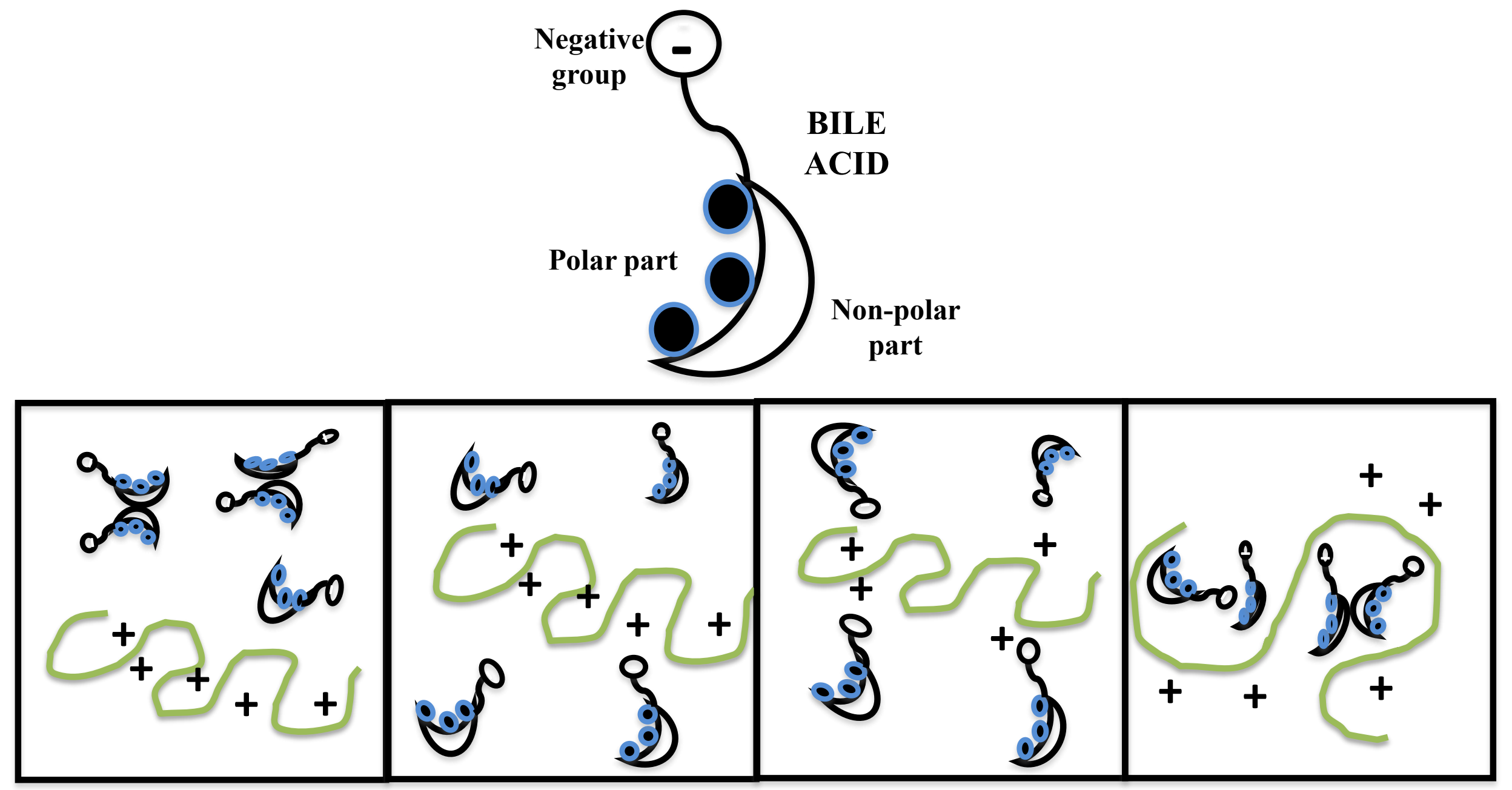
1. Monomers \& micelles
2. Demicellization. present immediately after injection.
3. Monomer binding.

\section{Conformation change $\&$ cluster formation.}

Fig. 5 Schematic diagram of the physicochemical processes occurring when bile salts are titrated into the reaction cell in the region where sodium taurocholate binds to the chitosan (Adapted from Thongnam and McClements 2005). 

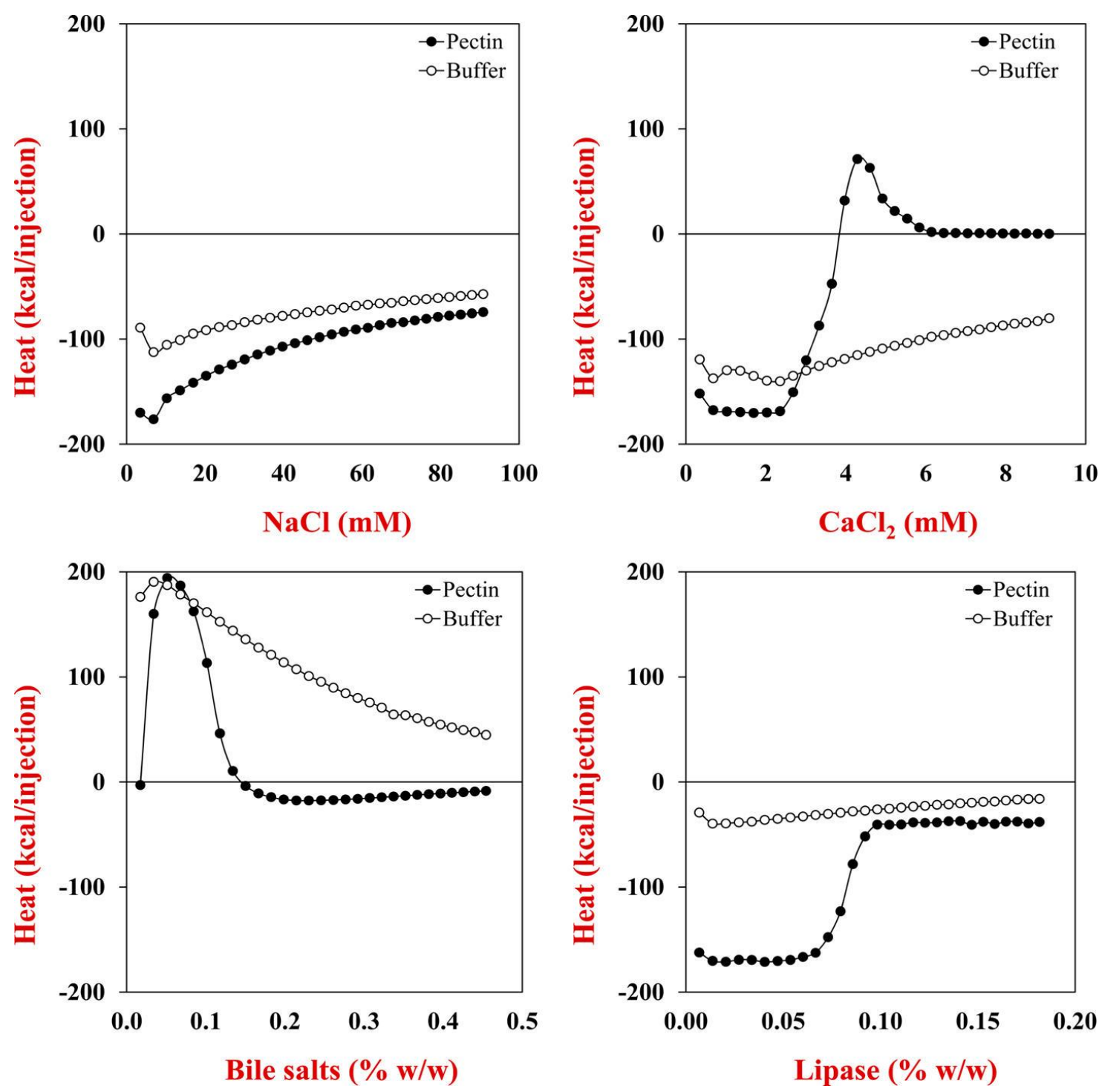

Fig. 6. Influence of the concentrations of $\mathrm{NaCl}, \mathrm{CaCl}_{2}$, bile salts, and lipase on interaction enthalpy $(\boldsymbol{\Delta} \mathbf{H})$ of solutions containing either buffer solution or an initial concentration of $0.9 \%(\mathrm{w} / \mathrm{w})$ pectin. Adapted with permission from Espinal-Ruiz et al., 2014. (Copyright 2014, American Chemical Society). 


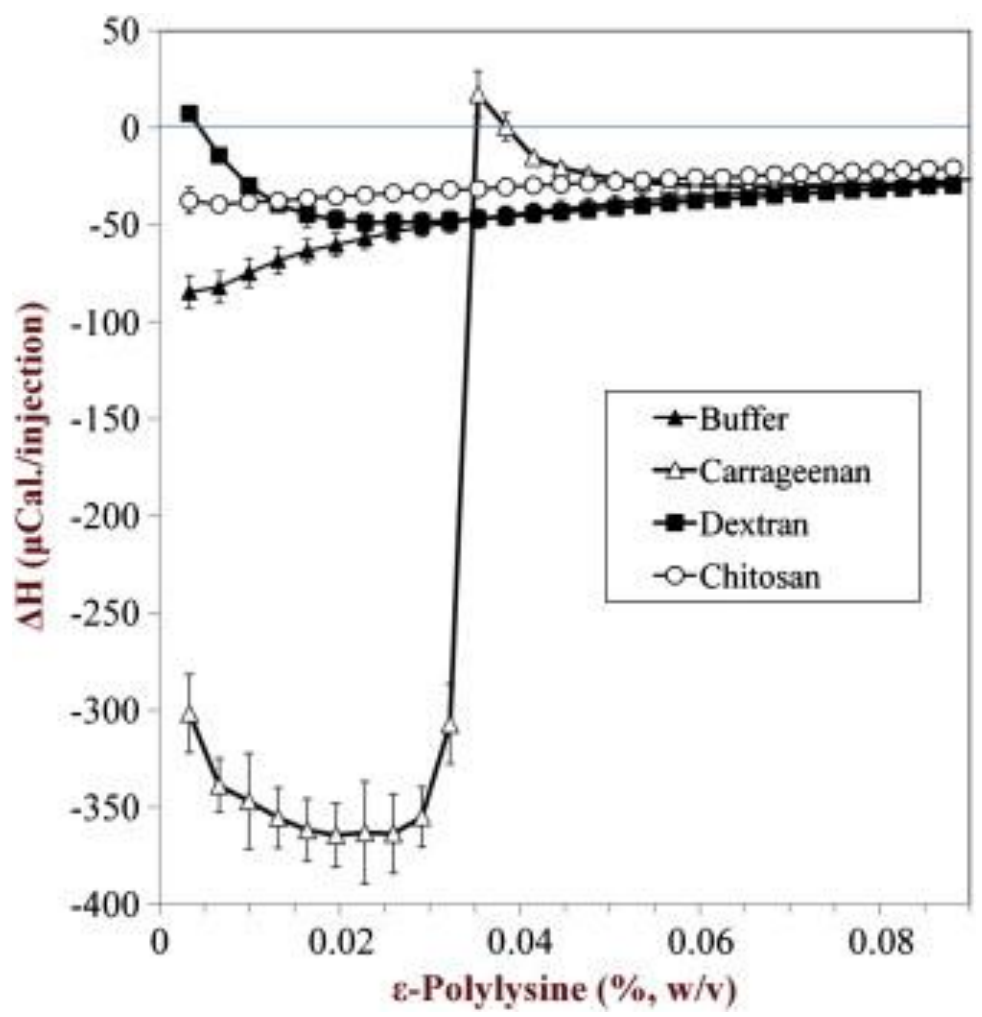

Fig. 7. Enthalpy change when cationic polylysine ( $\varepsilon-\mathrm{PL})$ is injected into a reaction cell containing different aqueous solutions at $\mathrm{pH} 3.5$ and $30.0{ }^{\circ} \mathrm{C}$ : buffer; $0.1 \%$ dextran (neutral); $0.1 \%$ chitosan (cationic); and $0.1 \%$ carrageenan (anionic). Data from Chang et al (2014). 